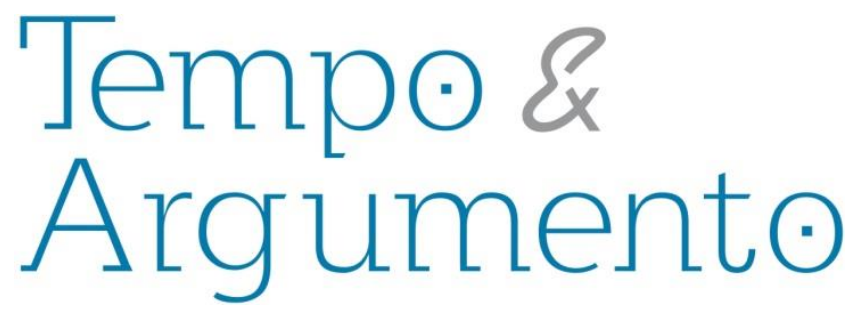

\title{
Os conceitos de lugar e território na composição do Patrimônio Cultural: Quilombos e terras indígenas na Constituição Federal brasileira $^{1}$
}

\begin{abstract}
Resumo
A vigente Constituição brasileira trata de direitos indígenas e quilombolas, tanto em relação à terra quanto à cultura. Mas, de maneira incoerente, desata as duas questões que são inerentes uma a outra. Atendendo a interesses políticos e econômicos, a Assembleia Nacional Constituinte, forjadora da Constituição, foi palco do imponderável descolamento do binômio lugar e território das práticas e bens culturais classificados como patrimônio. Para entender essa questão, uma revisão bibliográfica foi levantada com o intuito de demonstrar como essa separação presente no texto legal só pode ser justificada pela ótica do jogo político.
\end{abstract}

Palavras-chave: Assembleia Nacional Constituinte. Patrimônio Cultural. Direitos Quilombolas. Direitos Indígenas. Lugar e Território.

\section{Yussef Daibert Salomão de Campos}

Doutor em História pela Universidade Federal de Juiz de Fora (UFJF). Professor na Universidade Federal de Goiás (UFG). Goiânia - GO - Brasil yussefcampos@yahoo.com.br

\section{Para citar este artigo:}

CAMPOS, Yussef Daibert Salomão de. Os conceitos de lugar e território na composição do Patrimônio Cultural: Quilombos e terras indígenas na Constituição Federal brasileira. Tempo e Argumento, Florianópolis, v. 10, n. 25, p. 99 - 114, jul./set. 2018.

DOI: $10.5965 / 2175180310252018099$

http://dx.doi.org/10.5965/2175180310252018099

\footnotetext{
${ }^{1}$ Esse artigo é um dos frutos do estágio pós-doutoral desenvolvido pelo autor no Programa de Pósgraduação em Antropologia Social - UFG, supervisionado pela Prof ${ }^{a}$ Dr $^{\mathrm{a}}$ Izabela Tamaso
} 
The concepts of place and

territory in the composition

of Cultural Heritage:

Quilombos and indigenous

lands in the Brazilian Federal

Constitution

\begin{abstract}
The current Brazilian Constitution deals with indigenous and quilombo rights, both in relation to land and culture. But incoherently, it unties the two issues that are inherent in each other. In view of political and economic interests, the National Constituent Assembly, which forged the Constitution, was the scene of the imponderable detachment of the binomial place and territory of cultural practices and goods classified as heritage. In order to understand this question, a bibliographical review was raised with the intention of demonstrating how this separation present in the legal text can only be justified by the optics of the political game.
\end{abstract}

Keywords: National Constituent Assembly. Cultural Heritage. Quilombola Rights. Indigenous Rights.

Place and Territory. 
"(...) as place is sensed, senses are placed; as places make sense, senses makes place"

(Steven Feld, Waterfalls of song)

\section{Introdução}

A Assembleia Nacional Constituinte (ANC) brasileira, entre 1987 e 1988, apropriouse, entre tantos outros temas, do Patrimônio Cultural ${ }^{2}$. Após diversos embates e discussões que a perpassaram, a Constituição Federal foi construída e promulgada em outubro de 1988. Em seu corpo, a cultura está presente em diversos artigos, dentre eles, o 216 e o 231 que tratam, respectivamente, da normatização do patrimônio e dos direitos indígenas. Quero destacar aqui o parágrafo quinto $\left(\S 5^{\circ}\right)$ do 216 (e sua ligação direta com o artigo 68 do $\mathrm{ADCT}^{3}$ ) e do parágrafo primeiro $\left(\S 1^{\circ}\right.$ ) do 231 (junto ao $67 \mathrm{ADCT}$ ) pelas razões que passo a expor.

Determina o artigo 216 , $\S 5^{\circ}$ que "ficam tombados todos os documentos e os sítios detentores de reminiscências históricas dos antigos quilombos"4, enquanto o 68 ADCT dita que "aos remanescentes das comunidades dos quilombos que estejam ocupando suas terras é reconhecida a propriedade definitiva, devendo o Estado emitir-lhes os títulos respectivos".

Já o artigo 231, $\S 1^{\circ}$, implica que "são terras tradicionalmente ocupadas pelos índios as por eles habitadas em caráter permanente, as utilizadas para suas atividades produtivas, as imprescindíveis à preservação dos recursos ambientais necessários a seu bem-estar e as necessárias à sua reprodução física e cultural, segundo seus usos, costumes e tradições". E o artigo 67 ADCT determina que "a União concluirá a demarcação das terras indígenas no prazo de cinco anos a partir da promulgação da Constituição".

\footnotetext{
${ }^{2}$ Não será aqui aprofundada a questão sobre os atores sociais e políticos envolvidos no debate acerca de patrimônio na ANC, por não ser esse o objeto. Para isso, indico a seguinte referência: (CAMPOS, 2015).

3 Ato das Disposições Constitucionais Transitórias.

4 As normativas aqui utilizadas foram consultadas em: <http://www.senado.gov.br/atividade/const/ con1988 >, em: 30 de dezembro de 2017.
} 
Nesse momento da política governamental em matéria de "ordenamento do território" (BOURDIEU, 2007, p.110), o que cabe perquirir é: Por que os textos do artigo 216, $\S 5^{\circ}$ e do 68 ADCT estão separados se juntos foram propostos 5 ? E por que do artigo 231 foi retirada, do final da frase, a expressão "e do seu patrimônio cultural” se foi apresentada à ANC “(...) segundo seus usos, costumes e tradições e do seu patrimônio cultural"? Por que a demarcação e a emissão de propriedade não estão no corpo permanente da Constituição? Para Bourdieu, no "texto jurídico estão em jogo lutas" (2007, p.213), e no processo de construção desse texto, como a ANC, fazem-se expressar "lutas das representações", "lutas a respeito da identidade" (p. 113), a "dominação simbólica” (p. 117), "luta coletiva pela subversão das relações de forças simbólicas” (p. 124), "a conquista ou a reconquista de uma identidade" (p. 125). Certamente estamos diante do que Prats nomeou de "patrimônios incômodos" (2009, p. 89), não tendo o texto jurídico conseguido “dar vazão a toda uma complexa realidade fundiária que historicamente oprimiu e continua a fazê-lo quando se trata das territorialidades negras no Brasil” (LOBO; BERTUSSE, 2010, p. 206). Assim também se dá com a territorialidade indígena, convenientemente.

A impossível tarefa de se separar cultura e lugar, cultura e território foi empreendida pelo congressista constituinte, ao que, em outra oportunidade (CAMPOS, 2015), chamei de conveniência política pois, de um lado, atribuiu-se reconhecimento identitário às culturas até então marginalizadas pelas políticas públicas desenvolvidas através do patrimônio, mas por outro, postergou o enfrentamento da espinhosa Reforma Agrária ao se desvincular a emissão de propriedade quilombola e a conceituação de terras indígenas das práticas culturais a elas relacionadas, em dialética entre lugar e articulação política (GUPTA; FERGUSON, 2000, p. 33). “Daí a importância de localizar a análise no cerne do conflito" (TAMASO, 2006, p. 246).

\footnotetext{
5 "O artigo 25 do Projeto de Constituição (Fase Q), determinava que às 'comunidades negras remanescentes dos quilombos é reconhecida a propriedade definitiva das terras que ocupam, devendo o Estado emitir-lhes os títulos respectivos'. E sua segunda parte: 'Ficam tombadas essas terras, bem como todos os documentos referentes à história dos quilombos no Brasil'. A fase R encaminhou sua primeira parte para a parte transitória da Constituição, mas a segunda foi realocada" (CAMPOS, 2015, p. 145).
} 
Logo, o que esse artigo pretende é fazer uma breve revisão bibliográfica sobre os conceitos de lugar e de território, através de algumas leituras das Ciências Sociais (em especial Antropologia), Filosofia, História, Arqueologia e Geografia, sem, contudo, esgotá-las, para demonstrar o quão impossível é desvincular do Patrimônio, seja conceitualmente, seja na vivência dos grupos ou na gestão do patrimônio, tais conceitos. Como afirmou Casey (1996, p. 44)., "a potência de lugares inclui sua especificidade cultural". Com isso, será plausível indicar que a manobra feita durante o processo constituinte não foi de natureza aleatória, de sistematização normativa ou por adequação conceitual ou técnica. Tratou-se de atendimento a interesses políticos voltados a impedir, ou no mínimo adiar, a efetivação da posse e da propriedade das terras indígenas e quilombolas, como "elaborações retóricas por trás do patrimônio" (CÁCERES, 2013, p. 91). Por isso, podemos nos apoiar em Bhabha (2007, p. 166), ao apontar as reivindicações advindas da diversidade cultural como "estratégias legitimadoras de emancipação", lendo o "“cultural' como uma disposição de poder”

\section{Lugar e Patrimônio}

A incisiva frase de Yi-Fu Tuan (1983, p. 151) é capaz de resumir o que pretendo apresentar doravante: “o espaço transforma-se em lugar à medida que adquire definição e significado". Quando se humaniza o espaço, esse se torna lugar, afirma o geógrafo sinoamericano (TUAN, 1983, p. 61); o espaço construído pelo homem, com capacidade de aperfeiçoar a sensação e a percepção humana - afetada pela cultura - utilizado como recurso, torna-se apreciação cultural, torna-se lugar (TUAN, p. 114, p. 181, p. 65).

Nesse sentido, De Certeau (1998, p. 202), indica que se pratica o lugar com a função de fundar e articular espaços (DE CERTEAU, 1998, p. 208). É assim que se coloca "a cultura de volta ao lugar" (CASEY, 1996, p. 33) . Para Casey, o lugar é mais um evento do que algo para se compreender categorias (CASEY, 1996, p. 33). O lugar, afirma o filósofo, é "constituído por estruturas culturais e sociais que se sedimentam no mais profundo nível de percepção" (CASEY, 1996, p. 18). E emenda: “viver é viver localmente, e conhecer primeiro é conhecer os lugares em que se encontra" (CASEY, 1996, p. 15).

\footnotetext{
${ }^{6}$ As traduções foram feitas pelo autor.
} 
Para ilustrar, vejamos alguns casos de patrimonializações feitos pelo IPHAN ${ }^{7}$.

A cachoeira de lauaretê foi registrada, em $2006^{8}$, como patrimônio imaterial do Brasil por se tratar de Lugar sagrado dos povos indígenas dos Rios Uaupés e Papuri (AM). Como uma das justificativas, assim apresentou o IPHAN o bem cultural e a necessidade de sua salvaguarda:

O reconhecimento dos lugares sagrados dos povos que vivem na confluência dos Rios Uaupés e Papurí, na localidade conhecida como lauaretê, destaca a inesgotável capacidade desses povos indígenas criarem e recriarem suas tradições na perspectiva de um projeto histórico de resistência cultural. Nos lugares sagrados como as pedras, lajes e igarapés situados na Cachoeira de lauaretê e seu entorno, estão escritas as histórias de criação da humanidade e de ocupação do território em que eles vivem desde tempos imemoriais. Esses lugares indicam, igualmente, os códigos de manejo social organizadores da vida, tais como as formas de convivência e os mecanismos de transmissão dos saberes, identificadores das várias etnias que compartilham territórios e padrões culturais. (IPHAN, 2006, p. 11)

São nítidas as transformações do espaço em lugar, quando a cosmologia dos índios e a vivência em grupo modificam esse espaço, construído e alterado pela percepção e pela cultura, tornando-se evento repleto de significado e definição.

Outra exemplificação relevante: "é notável que vários dos bens culturais registrados como patrimônio cultural nacional sejam encontrados em comunidades quilombolas, tais como o Jongo no Sudeste, o Samba de Roda do Recôncavo Baiano, o Complexo Cultural do Bumba-meu-Boi do Maranhão, dentre outros" (VAZ, 2016). O Patrimônio é holístico: não só o quilombo, em si, é passível de patrimonialização, mas ele é o lugar de cultivo de expressões culturais diretamente a ele vinculadas. Como propôs Casey (1996, p. 34), "ser cultural, ter uma cultura, é habitar um lugar suficientemente intenso para cultivá-lo". Lugar "humanizado e humanizante", é o que aponta Malpas, a partir de sua leitura de Heaney (MALPAS, 1999, p. 29). Entendamos, portanto, que as pessoas habitam os lugares e os lugares habitam as pessoas.

\footnotetext{
7 Instituto do Patrimônio Histórico e Artístico Nacional.

8 Pedido de Registro aprovado na $49^{\text {a }}$ reunião do Conselho Consultivo do Patrimônio Cultural, em 03/08/2006. Inscrição no Livro dos Lugares em 10/08/2006 (IPHAN, 2006, p. 7).
} 
Com isso, é possível entender o porquê das exigências pelos lugares. Eles são “politizados, culturalmente relativizados, historicamente específicos” (RODMAN, 2003, p. 205); são forjados de cultura e história (RODMAN, 2003, p. 208). O lugar é repleto de identidade. Ele pode ser definido como "lugar de identidade, relacional e histórico" (AUGÉ, 2008, p. 83). É o que Salgado (2013, p. 39), denomina "habitat de significado" repleno de emoções, história(s), afetos, que designam “o conceito simbólico e afetivo da produção da identidade pessoal” (SALGADO, 2013, p. 39), sentidos esses constituintes primordiais da “identidade com o lugar” (CÁCERES, 2013, p. 94). Mas não só a identidade individual. O lugar é fundamental para a formação de identidades sociais (BASSO, 1996, p. 53), que podem ser experienciadas (BASSO, 1996, p. 56). Entretanto, esse lugar de vivências (CÁCERES, 2013, p. 94) é também lugar de disputa, e sobre o qual se disputa. São construídos, mas são também contestados e impostos (GUPTA; FERGUSON, 2000, p. 32). Isso pode nos levar a trabalhar também o conceito de território.

Quando a Assembleia Nacional Constituinte amputa os textos referidos na introdução desse texto, ela está matando todo o sentido do lugar, "sentido do lugar político" (JACKSON, 1994, p. 151), além de esvaziar de sentido os patrimônios neles citados ou omitidos. A partir da cultura como disposição de poder e das reclamações identitárias como estratégias legitimadoras de emancipação, Bhabha (2007, p. 166) discorre que "ver o cultural não como fonte do conflito - culturas diferentes - mas como o efeito de práticas discriminatórias - a produção de diferenciação cultural como signos de autoridade - muda seu valor e suas regras de reconhecimento"

É impossível separar a ingerência do poder econômico e político da construção social do lugar (CÁCERES, 2013, p. 93). A ANC produziu uma perversidade normativa: a partir das manobras já explicitadas, ela se utiliza da disputa pela terra enquanto fonte do conflito, gerando no patrimônio cultural o efeito da prática discriminatória da não atribuição de propriedade aos quilombolas ou da demarcação para os indígenas. Essa absoluta não negociação da cultura, da identidade e do passado (TILLEY, 2006, p.15) permitiu as constantes práticas de violência cometidas contra quilombolas e indígenas, desde a grilagem de terras ao extermínio coletivo de grupos que legitimamente ocupam seu lugar, sem, todavia, o amparo efetivo do Estado. 
O quilombo e a terra indígena são, indubitavelmente, lugares. O "saber do patrimônio é sempre um saber dos lugares" (POULOT, 2008, p. 29). Lugares que se disputam “como "comunidade”" (LACARRIEU, 2013, p. 23). Mas são também território. Lugar e território são conceitos próximos, mas que não se confundem. Diferentemente do lugar, o território deve ser analisado pela perspectiva política de disputas materiais pelo espaço. Por isso, passo a tratar desse conceito.

\section{Território e patrimônio}

Haesbert apresenta-nos a seguinte concepção: "o território pode ser concebido a partir da imbricação de múltiplas relações de poder, do poder mais material das relações econômico-políticas ao poder mais simbólico das relações de ordem mais estritamente cultural" (2004a, p. 79). Nos casos tratados neste artigo, perpassa-se das relações econômico-políticas às relações de ordem cultural. Não numa lógica evidente, mas no uso de ambas para uma superficial impressão de atendimento às reivindicações presentes na ANC, porém manchada pela desconexão incoerente entre patrimônio e território.

Para Dias (2010, p. 262), “é imprescindível interpretar e salientar as concepções de territorialidade que embasam a ocupação de povos e comunidades tradicionais, assim como sua posição acerca das decisões que lhes dizem respeito", como a vinculação óbvia de suas práticas culturais à terra. Adita que entende "territorialidade no sentido de Paul Little (2002), como sendo 'o esforço coletivo de um grupo social para ocupar, usar, controlar, e se identificar com uma parcela específica de seu ambiente biofísico, convertendo-a assim em seu território"' (LITTLE, 2002: 03) (p. 262).

Território associa-se à integridade e à subsistência (APPADURAI, 2003, p. 340), à identidade (p. 346), portanto é uma categoria que "reforça o direito à titulação presente no artigo 68 do ADCT" (JORGE, 2016, p. 122).

Isto porque, esta ultrapassa a noção de que a "questão quilombola" teria em seu conteúdo apenas a demanda por resolução de conflitos agrários. Tal categoria enseja, segundo os antropólogos, a representação de uma diversidade ampla de saberes tradicionais, práticas sustentáveis de uso dos recursos naturais, e uma organização social própria vinculada ao uso deste espaço. Nessa chave interpretativa, as comunidades 'quilombolas' 
seriam grupos diferenciados porque tem sua reprodução social, cultural e material vinculadas a este espaço socialmente apropriado. Assim, o território seria mais um elemento identitário para a nomeação das comunidades 'quilombolas' como coletividades diferenciadas. Essa categoria atualiza mais uma vez o discurso antropológico: as comunidades 'quilombolas' são grupos diferenciados por terem um vínculo com o espaço onde se encontram. Este espaço traduz o sentimento de pertença, os laços de parentesco, a herança de seus antepassados. Tal espaço possuiria um valor afetivo, material, e coletivo para estes grupos, segundo a leitura antropológica. (JORGE, 2016, p. 121122)

Jorge aponta para a mesma direção que a minha ao tratar de quilombolas numa análise que podemos estender à questão indígena. Nomeia a divisão do artigo 216 do artigo 68 ADCT de "formulação 'amputada"' (2016, p. 35), (assim como a feita com os artigos 231 e 67 da ADCT), que teria "sido aprovado sem maiores discussões, tendo como ‘caldo ideológico' o Centenário da Abolição (p. 35). A “falsa antítese” (p. 44) sugerida pela dicotomia “dimensão agrária” X “dimensão cultural”, fez com que um campo superasse o outro, a partir dos interesses políticos em jogo, pois a "bipartição da disposição constitucional acerca dos quilombos apontava já para uma primazia da dimensão cultural sobre a agrária, dada pela valorização do artigo 216 em relação ao artigo 68 do ADCT" (p. 43-44).

Para esses grupos, a posse do território "é a certeza de assegurar a manutenção de sua identidade” (MÜLLER, 2010, p. 90); “o território, a utilização dos recursos naturais, as práticas religiosas e culturais, estão relacionadas” (FARIAS JR., 2010, p. 119). Todavia, o território "deriva de estratégias de domínio e controle", através de "relações de poder" (SAQUET, 2007, p. 66). Ainda que as identidades indígenas e quilombolas apresentem-se, no espectro político, como identidades resilientes, a omissão do Estado, tanto no processo constituinte quanto após a promulgação da Carta de 1988, gera assassínios e expropriações de terra que colocam em sério risco a sobrevivência desses grupos. A territorialidade, enquanto "dimensão da nação moderna" tem que ser meio para se “construir geografias morais” (APPADURAI, 2003, p. 337).

Com o esclarecimento de Gomes (2010), no qual aponta o risco de perda de direitos à terra como consequência do afrouxamento da redação dos artigos 
constitucionais anteriormente apresentados, creio poder intentar o fechamento das exposições deste artigo, destacando que a territorialidade só pode ser analisada a partir da "apreensão das relações reais colocadas no seu contexto sócio-histórico e espaçotemporal (RAFFESTIN, p. 162, 1993)".

\begin{abstract}
Apesar de estarmos diante de um inegável patrimônio histórico e cultural, as ameaças de perda de seus direitos têm sido constantes a partir de diversas arenas de embates. A Bancada Ruralista, principal portadora de ações contrárias à efetivação desses direitos, lança mão de artifícios diversos com o objetivo de bloquear o mesmo. No Congresso Nacional tramitam diversas leis contrárias ao direito quilombola podendo-se citar a PDC 44/2007 e PDC 326/2007, ambas propostas pelo Deputado Valdir Colatto (PMDB/SC). No Supremo Tribunal Federal está para ser votada a ADIN 3239/2004 impetrada pelo PFL (atual DEM) contra o Decreto 4887/2003. A pergunta a ser feita é: como é possível retroceder em um direito garantido na Constituição e reconhecidamente legítimo uma vez que é fruto de um processo de territorialização que se constitui em patrimônio histórico e cultural de toda a sociedade brasileira? (GOMES, p. 188)
\end{abstract}

\title{
Notas finais
}

A perversidade Constituinte em relação ao lugar e ao território quilombola e indígena é apresentada, em síntese, nas seguintes ações: a sistematização do trabalho constituinte dividiu os temas afins à questão em "Ordem Social”, "Ordem Política", "Ordem Econômica", dividindo e enfraquecendo os movimentos pois, aqueles que participassem de um debate sobre racismo ou inclusão, por exemplo, talvez se ausentassem de debates sobre patrimônio ou sobre reforma agrária, já que esses temas se diluíram nessas "ordens" do processo constituinte; a separação dos artigos hierarquizou, politicamente, cultura, lugar e território, fazendo com que a demarcação e a emissão do título de propriedade ficassem sem a adequada regulamentação; ao tratar os quilombos como reminiscências, obliterou sua dimensão social, reduzindo-os à perspectiva histórica; prevaleceu a questão cultural sobre a agrária; o não enfrentamento direto é mancha no processo da ANC, pois “apesar de serem normas constitucionais, os ADCT's marcam um leque de questões que durante a aprovação da Constituição não haviam ficado claras, ou não restava mais tempo para o debate" (JORGE, 2016, p. 38). 
Não há como falar em patrimônio sem localizá-lo. O lugar e o território são intrínsecos à própria noção de patrimônio. Ao tratar da categoria intangível, Antonio Arantes (2017) ${ }^{9}$. afirmou que os corpos humanos são o território mínimo do patrimônio cultural imaterial ${ }^{10}$. Para Hall (1977, p. 96), “o território é, em todas as acepções da palavra, uma extensão do organismo, marcada por signos visuais, vocais e olfativos. 0 homem criou extensões materiais da territorialidade, bem como marcadores territoriais visíveis e invisíveis"

Logo, o que o constituinte fez através de sua "ortodoxia normativa" (PRATS, 2009, p. 91), ou como prefere Leite (2010, p. 18), da “ordem jurídica hegemônica”, apesar da ampliação do conceito de patrimônio cultural, foi, quanto a quilombolas e indígenas, demonstrar a "simulação social” e as "operações de ritualização cultural" (GARCíA CANCLINI, 2008, p. 160; p. 192) por meio do não reconhecimento dos direitos ligados à terra, "instituindo uma diferença duradoura entre os que participam e os que ficam de fora" (GARCÍA CANCLINI, p. 192). Tornou-se mais um exemplo de como o "patrimônio cultural funciona como recurso para reproduzir as diferenças entre os grupos sociais e a hegemonia dos que conseguem um acesso preferencial à produção e à distribuição dos bens" (GARCÍA CANCLINI, p. 195).

Para Cabral (2011, p. 51), há uma “(...) necessidade de deixar bem claro o direito das populações indígenas à autodeterminação e a viver de acordo com a sua cultura, bem como a relação entre identidade cultural e território". Para Leite, "o direito "quilombola" que a Constituição Brasileira visa alcançar é o direito sobre o lugar, o direito não exclusivamente à terra ou às condições de produção, mas sobretudo o seu reconhecimento na ordem jurídica que é, antes de tudo, uma política de direitos humanos" (2010, p. 36).

É a vitória dos detentores do poder econômico e político sobre os excluídos das políticas públicas. Um estado realmente democrático é aquele aberto aos aperfeiçoamentos vindos de baixo, disse Florestan Fernandes, (2015, p. 99). Contudo, a

\footnotetext{
9 Palestra proferida no evento "Seminário Internacional O Futuro do Patrimônio", em comemoração aos 80 anos do IPHAN. 27 de outubro de 2017, Museu do Amanhã, Rio de Janeiro.

${ }^{11}$ Organização Internacional do Trabalho.
} 
ANC foi palco, uma vez mais, de tratativas excludentes, reacionárias e degradantes, embora tenha também, em outros temas, alcançado metas progressistas.

O próprio artigo 216 é um avanço. Contudo, a sistematização perversa que destituiu da cultura sua relação com a terra implicou em efeitos catastróficos para as populações indígenas e quilombolas do país. A Ação Direta de Inconstitucionalidade (ADI 3239) que corre no Supremo Tribunal Federal é um exemplo da permanência das posições conservadoras dos donos da terra e do poder. Nele, busca-se a invalidação do decreto 4887/2003, que regulamentou o artigo 68 ADCT. Acredito que se esse conteúdo estivesse no corpo permanente da Constituição, haveria maior força política do dispositivo, embora não haja hierarquia jurídica entre os artigos do corpo permanente e do corpo transitório. Assim como acredito que seriam menos prováveis e/ou mais fracas politicamente a Proposta de Emenda à Constituição (PEC) 215/200, que propõe retirar do Poder Executivo a exclusividade na demarcação de terras indígenas, e a PEC 1610/1996, que trata da autorização de exploração mineral nessas terras.

Cumpre ressaltar que o Brasil é signatário da Convenção $\mathrm{n}^{0} 169$ da OIT ${ }^{11}$, sobre povos indígenas e tribais, ratificada em julho de 2002, cujo artigo 14 determina que "os direitos de propriedade e posse de terras tradicionalmente ocupadas pelos povos interessados deverão ser reconhecidos" (2011, p. 23).

Afirmou Benjamin (2012, p. 244), mostrando a capacidade da perpetuação de suas ideias, que "todos os que até agora venceram participam do cortejo triunfal, que os dominadores de hoje conduzem por sobre os corpos dos que hoje estão prostrados no chão. Os despojos são carregados no cortejo triunfal, como de praxe. Eles são chamados de bens culturais".

\footnotetext{
${ }^{11}$ Organização Internacional do Trabalho.
} 


\section{Referências}

APPADURAI, Arjun. Sovereignty without territoriality: notes for a posnational geography. In: LOW, Setha; LAWRENCE-ZÚNIGA, Denise. The anthropology of space and place: locating culture. Oxford: Blackwell Publishing, 2003. p. 337-350.

AUGÉ, Marc. Los no lugares: espacios del anonimato - una antropología de la sobremodernidad. Barcelona: Gedisa Editorial, 2008.

BASSO, Keith. Wisdom sits in places: notes on a western apache lanscape. In: FELD, Steven; BASSO, Keith (Orgs.) Senses of Place. Santa Fé, Novo México: School of American Research Press, 1996. p.53-90.

BENJAMIN, Walter. Magia e técnica, arte e política: ensaios sobre literatura e história da cultura. $8^{\mathrm{a}}$ ed. Ver. São Paulo: Brasiliense, 2012.

BHABHA, Homi. O local da cultura. Belo Horizonte: Editora UFMG, 2007.

BOURDIEU, Pierre. O poder simbólico. 11ª ed. Rio de Janeiro: Bertrand Brasil, 2007.

CABRAL, Clara Bertrand. Património cultual imaterial. Lisboa: Edições 70: Arte \& Comunicação, 2011.

CÁCERES, Luz Stella Rodriguez. Naturezas monumentalizadas, cotidianos politizados: a construção discursiva do lugar no caso do Quilombo Sacopã. Revista Sociedade e Cultura, v. 16, n. 1. p. 91-106, jan./jun., 2013.

CAMPOS, Yussef Daibert Salomão. A dimensão política do patrimônio cultural na constituinte de 1987-1988. 2015. Tese (Doutorado em História) - Instituto de Ciências Humanas e Letras, Universidade Federal de Juiz de Fora, 2015.

CASEY, Edward S. How to get from space to place in a fairly short stretch of time. Phenomenological prolegomena. In: FELD, Steven; BASSO, Keith (Orgs.) Senses of place. Santa Fé, Novo México: School of American Research Press, 1996.p.13-52.

DE CERTEAU, Michel. Práticas de espaço: a invenção do cotidiano. Petrópolis: Vozes, 1998.

DIAS, Guilherme Mansur. Reconhecimento e diversidade na llha de Saracura, Pará. In: ALMEIDA, Alfredo Wagner Berno de et al. (Orgs) Nova cartografia social: territórios quilombolas e conflitos. Manaus: Projeto Nova Cartografia Social da Amazônia / UEA Edições, 2010. p. 251-265. 
FARIAS Jr. Emmanuel de Almeida. Unidades de conservação, mineração e concessão florestal: os interesses empresariais e a intrusão de territórios; Quilombolas no Rio Trombetas. In: ALMEIDA, Alfredo Wagner Berno de et al. (Orgs). Nova cartografia social: territórios quilombolas e conflitos. Manaus: Projeto Nova Cartografia Social da Amazônia / UEA Edições, 2010. p. 117-139.

FELD, Steven. Waterfalls of song. An acoustemology of place resounding in Bosavi, Papua New Guinea. In: FELD, Steven; BASSO, Keith (Orgs.) Senses of place. Santa Fé, Novo México: School of American Research Press, 1996.p.91-135.

GARCÍA CANCLINI, Néstor. Culturas híbridas: estratégias para entrar e sair da modernidade. $4^{\text {a }}$ ed. São Paulo: Editora da Universidade de São Paulo, 2008.

GOMES, Lílian. Justiça seja feita: direito quilombola ao território. In: ALMEIDA, Alfredo Wagner Berno de et al. (Orgs). Nova cartografia social: territórios quilombolas e conflitos. Manaus: Projeto Nova Cartografia Social da Amazônia / UEA Edições, 2010. p. 186-195.

GUPTA, Akhil; FERGUSON, James. Mais além da cultura: espaço, lugar e política da diferença. In: ARANTES, Antonio Augusto (Org.). O espaço da diferença. Campinas: Papirus, 2000. p. 30-49.

HALL, Edward. A dimensão oculta. Rio de Janeiro: Livraria Francisco Alves, 1977.

IPHAN. Dossiê IPHAN 7 - Cachoeira de lauaretê - Lugar sagrado dos povos indígenas dos Rios Uaupés e Papuri (AM). Brasília: IPHAN, 2006.

JACKSON, John B. A sense of place, a sense of time. New Haven and London: Yale University Press, 1994.

JORGE, Amanda Lacerda. O processo de construção da questão quilombola: discursos em disputa. Rio de Janeiro: Gramma, 2016.

LACARRIEU, Monica, Entre el “Lugar Antropológico” y el “Lugar Disputado”: Hacia una “Antropología del lugar”. Sociedade e Cultura, Goiânia, v. 16, n. 1, p. 15-26, jan./jun. 2013.

LEITE, Ilka Boaventura. Humanidades insurgentes: conflitos e criminalização dos quilombos. In: ALMEIDA, Alfredo Wagner Berno de et al. (Orgs). Nova cartografia social: territórios quilombolas e conflitos. Manaus: Projeto Nova Cartografia Social da Amazônia / UEA Edições, 2010. p. 18-40.

LOBO, Janaina Campos; BERTUSSE, Mayra Lafoz. O Legal e o Local: Relações de Poder, Conflitos e a Titulação da Terra na Comunidade Quilombola de Palmas/ Bagé-RS. In: 
ALMEIDA, Alfredo Wagner Berno de et al. (Orgs). Nova cartografia social: territórios quilombolas e conflitos. Manaus: Projeto Nova Cartografia Social da Amazônia / UEA Edições, 2010. p. 205-208.

MALPAS, Jeff. Place and experience: a philosophical topography. Cambridge: Cambridge University Press, 1999.

MÜLLER, Cíntia Beatriz. A utilização de meios alternativos de solução de conflitos em processos de territorialização: casos de Alcântara e Marambaia. In: ALMEIDA, Alfredo Wagner Berno de et al. (Orgs). Nova cartografia social: territórios quilombolas e conflitos. Manaus: Projeto Nova Cartografia Social da Amazônia / UEA, Edições, 2010. p. 88-100.

ORGANIZAÇÃO INTERNACIONAL DO TRABALHO. Convenção n 169 sobre povos indígenas e tribais e Resolução referente à ação da Organização Internacional do Trabalho. Brasilia: OIT, 2011.

POULOT, Dominique. Um ecossistema do patrimônio. In: CARVALHO, C. S. R.; GRANATO, M.; BEZERRA, R. Z.; BENCHETRIT, S. F. Um olhar contemporâneo sobre a preservação do patrimônio cultural material. Rio de Janeiro: Museu Histórico Nacional, 2008. p.26-43.

PRATS, Llorenç. Antropología y patrimônio. Barcelona: Ariel Antropología, 2009.

RAFFESTIN, Claude. Por uma geografia do poder. São Paulo: Editora Ática, 1993.

RODMAN, Margaret C. Empowering Place: multilocatity and multivocality. In: LOW, Setha; LAWRENCE-ZÚNIGA, Denise. The anthropology of space and place. Locating Culture. Oxford: Blackwell Publishing, 2003. p. 204-223.

SALGADO, Ricardo Seiça. O habitat de significado do não-lugar como espaço político e performativo concreto. Revista Sociedade e Cultura, Goiânia, v. 16, n. 1, p. 37-46, jan./jun., 2013.

TAMASO, Izabela. A Cruz do Anhanguera: representações, experiências, memórias, patrimônio. In: FRÙGOLI JR., Heitor; ANDRADE, Luciana T. de; PEIXOTO, Fernanda A. (Orgs.) A cidade e seus agentes: práticas e representações. Belo Horizonte: Ed. PUC Minas; São Paulo: Edusp, 2006, p. 245-273.

TILLEY, Christopher. Introduction: Identity, Place, Landscape and Heritage. Journal of Material Culture. v. 11, n.1/2, p. 7-32, 2006.

TUAN, Yi-Fu. Espaço e lugar: a perspectiva da experiência. Tradução de Lívia de Oliveira. São Paulo: Difel, 1983. 
VAZ, Beatriz Accioly. Quilombos. In: GRIECO, Bettina; TEIXEIRA, Luciano; THOMPSON, Analucia (Orgs.). Dicionário IPHAN de patrimônio cultural. 2. ed. rev. ampl. Rio de Janeiro, Brasília: IPHAN/DAF/Copedoc, 2016.

Recebido em 11/03/2018 Aprovado em 14/06/2018

Universidade do Estado de Santa Catarina - UDESC

Programa de Pós-Graduação em História - PPGH

Revista Tempo e Argumento Volume 10 - Número 25 - Ano 2018 tempoeargumento@gmail.com 